\title{
CoviD-19 Rostering in a pandemic: Sustainability is key
}

\author{
Authors: Matthew Roycroft, ${ }^{\mathrm{A}}$ Neeraj B Bhala, ${ }^{\mathrm{B}}$ Susannah Brockbank,, Donal O’Donoghue, ${ }^{\mathrm{D}}$ Andrew Goddard ${ }^{\mathrm{C}}$ and \\ Ajay M Verma ${ }^{F}$
}

\begin{abstract}
In preparation for the peak of the first wave of COVID-19, many healthcare organisations implemented emergency rotas to ensure they were adequately staffed. These rotas while addressing the acute issues - are in many cases not sustainable. As we move past the peak and services start resuming, many organisations need to reassess their rotas. There are considerable wellbeing benefits to optimal rostering. In this article we discuss how best to achieve this and suggest a number of key principles, including the following: involvement of staff affected by the rota; taking into account individual circumstances; building in flexibility and adequate time for rest; and designing rotas for different grades of staff together to create stable teams.
\end{abstract}

KEYWORDS: Rostering, rotas, leave, COVID-19

DOI: 10.7861/fhj.2020-0065

\section{Introduction}

COVID-19 has had significant impact upon the healthcare system, with marked increases in demand for care in some areas, coupled with significant reductions in others. Many organisations introduced emergency rosters for doctors of all grades in preparation for the influx of COVID-19 cases. Frequently there were significant changes in policy regarding leave, including in some cases cancellation of annual and study leave. Roster changes have varied between organisations and even between departments, with some

Authors: AST7 in geriatric medicine, Northern General Hospital, Sheffield, UK and co-chair of the Trainees Committee, Royal College of Physicians, London, UK; ${ }^{\mathrm{B}}$ Consultant physician and gastroenterologist, Queen Elizabeth Hospital and University Hospital Birmingham NHS Foundation Trust, Birmingham, UK; ' ST6 in rheumatology, Mid Cheshire Hospitals NHS Trust, and clinical research fellow, University of Liverpool, Liverpool, UK; DConsultant nephrologist, Salford Royal Hospital, Manchester, UK and registrar, Royal College of Physicians, London, UK; ${ }^{E}$ Consultant gastroenterologist, Royal Derby Hospital, Derby, UK, and president, Royal College of Physicians, London, UK; ${ }^{F}$ consultant gastroenterologist, Kettering General Hospital, Kettering, UK, and chair of the New Consultants Committee, Royal College of Physicians, London, UK continuing unchanged, some seeing minor adaptations, and others resorting to significant adaptations with onerous out-of-hours commitments.

We have moved past the first peak ${ }^{1}$ but may still be at an early stage of the pandemic. Continuing to work at an intense level is not sustainable. Below we explore the changes organisations need to consider moving forward to ensure longer-term workforce wellbeing and optimal functioning.

\section{Mental health and wellbeing}

The mental health and wellbeing of healthcare professionals is at significant risk during and after the COVID-19 pandemic: acute stress, burnout, bereavement reactions, anxiety, depression, moral distress and post-traumatic stress disorder have all been predicted. ${ }^{2-4}$ It is important to prioritise wellbeing and mental health, and indeed prevention is at the heart of guidance. ${ }^{5}$ Sustainable working patterns - including adequate periods of rest during and between shifts ${ }^{6}$ - are fundamental to preserving the wellbeing of the workforce through the pandemic, ${ }^{7}$ and can be supplemented by development of a team ethos and adequate provision of facilities, including places to rest during shifts. ${ }^{8}$ This needs to be balanced with providing a functioning service to deal with the COVID-19 pandemic. Reinstitution of previous educational and mentoring leadership roles, such as royal/associate college tutors, may help with this.

\section{Rest and recuperation: annual and study leave}

Short-term blanket cancellation of leave to deal with the COVID-19 pandemic crisis may have been an appropriate emergency step in some organisations, but is not sustainable moving forward. While cancellation may be lawful, ${ }^{9}$ and national rules have been relaxed to allow staff to roll over annual leave, ${ }^{10}$ no national body is advocating for preventing leave entirely. As services resume, so should taking leave. Though the most common reasons for taking annual leave - such as travel and attending gatherings - are currently limited, healthcare workers still need meaningful time away from work to prevent negative effects on their wellbeing, performance and outcomes. Staff who have worked intensive surge rotas or were redeployed to high acuity areas may benefit from additional leave to allow for recovery and processing of difficult experiences.

Annual leave allocations should, as far as possible, be facilitated, though perhaps with more frequent, shorter periods to allow 
Key points: Suggestions for developing sustainable rosters during the COVID-19 pandemic

The individuals involved in rota design should have experience of doing so. There needs to be a full awareness of service requirements, staffing levels, leave and contractual obligations. In addition, we suggest taking account of the following principles.

$>$ Meaningful consultation of affected staff.

$>$ Ensuring that no one grade of doctor is disproportionately burdened.

> Considering individual circumstances, including personal, physical, and psychological needs.

> Taking account of the fact that individual risk assessments may necessitate staff at high risk coming off on-call rosters they can support their colleagues in other ways.

> Building flexibility into rotas to allow for absences or overstaffing. This flexible time could be used for rest and selfcare, seeking psychological support, or similar.

$>$ Aiming to work in teams with a clear function and structure. Stable teams may identify signs of burnout in colleagues who are unaware themselves - thus helping to manage it earlier.

$>$ Rotating staff between high and low intensity environments. ${ }^{11}$

$>$ Clearly prescribing breaks within shifts to allow for rest and refreshments, recognising that these are more important now than ever.

$>$ Ensuring adequate time for rest, decompression and recovery after shifts; this is critical and needs to be commensurate to the intensity of the shift worked.

> Ensuring facilities needed for staff to work are in place (parking, refreshment, rest, changing, etc).

> Permitting and actively encouraging leave requests, especially annual leave, and following appropriate national guidance when making changes to usual practice..$^{9,10,12}$

$>$ Ensuring opportunities for CPD continue.

> Being aware that those coming back from redeployment, especially from high-intensity environments, may not have been able to take leave while in those settings and thus need their leave prioritising.

$>$ Clearly communicating the rationale of rostering/leave decisions.

individuals to rest at home. The experience of taking leave is not necessarily the same for everyone: for example, some will be able to spend time with their family during this worrying time, while others may be unable to do so due to the need to isolate or follow social distancing rules. Many workers, whether due to a sense of duty or because they are socially isolated away from work, may be reluctant to take leave. Supervisors need to understand and consider individual circumstances, and on occasion may need to actively encourage staff to take time off. Annual leave should only be cancelled in the future if absolutely necessary, and only for a short period of time (less than a month). It is likely that staff will be unable to take accrued leave and hence must be compensated for untaken leave. Ideally, decisions regarding leave cancellation should be made at a high level, and in consultation with the affected workforce to ensure staff do not feel devalued by the decision.

Professional and study leave have been uniformly cancelled so as not to impair healthcare provision and to allow social distancing, leading to the loss of local training, regional and national meetings. Continued professional development and leadership roles will be as important as ever during the coming months, particularly given that knowledge will help combat the fear of the unknown. Therefore, some provision for professional and study leave needs to be allowed if possible, perhaps to enable the delivery of updates and training around the COVID-19 pandemic itself, now and as services recover. There are many examples of 'side-skilling' in the physician workforce, be it intensive care working, frontline and palliative care, and new ways of working (eg telephone clinics). These skills will be utilised both for ongoing learning and to provide flexibility in the future, enabling the healthcare system to re-adapt if future pandemic peaks occur.

Sick leave and compassionate leave will have to remain available and accounted for in rota planning, at higher levels than normal. Many health care professionals and their loved ones will be infected with COVID-19 themselves, with a range of consequences inevitably affecting sustainable workforce planning. Even in the face of uncertainty regarding the magnitude of the pandemic, we need to empower colleagues to take ownership of providing a sustainable, kind and safe work environment. After all, beyond COVID-19, we need a healthcare workforce that has the capacity to go on, perhaps bruised but unbroken.

\section{References}

1 Prime Minister's Office. Coronavirus press conference slides (4 May 2020). Available from https://twitter.com/10DowningStreet/ status/1257354002024615936 [Accessed 5 May 2020].

2 Farquhar M, Unadkat S. Doctors' wellbeing: self-care during the Covid-19 pandemic. BMJ 2020;368:m1150.

3 Walker C, Gerada C. Extraordinary times: coping psychologically through the impact of Covid-19. BMJ Opinion 2020. Available from https://blogs.bmj.com/bmj/2020/03/31/extraordinary-timescoping-psychologically-through-the-impact-of-covid-19/ [Accessed 4 April 2020].

4 Greenberg N, Docherty M, Gnanapragasam S, Wessely S. Managing mental health challenges faced by healthcare workers during covid-19 pandemic. BMJ 2020;368:m1211.

5 National Institute for Health and Care Excellence. Workplace health: management practices [NG13]. NICE 2015, updated 2016. Available from www.nice.org.uk/guidance/ng13 [Accessed 1 April 2020].

6 NHS Staff Council's Health, Safety and Wellbeing Partnership Group (HSWPG). Supporting the wellbeing of shift workers in healthcare. NHS Employers, 2020. Available from www. nhsemployers.org/case-studies-and-resources/2020/02/the-healthsafety-and-wellbeing-of-shift-workers-in-health-care-environments [Accessed 6 April 2020].

7 Chen Q, Liang M, Li Y et al. Mental health care for medical staff in China during the COVID-19 outbreak. Lancet Psychiatry 2020;7:e15-6.

8 British Medical Association. BMA Fatigue and Facilities charter. BMA, 2018. Available from www.bma.org.uk/media/1076/bmafatigue-and-facilities-charter_july2018.pdf [Accessed 5 April 2020].

9 British Medical Association. COVID-19: your terms and conditions. Updated 6 May 2020. BMA, 2020. Available from www.bma.org. uk/advice-and-support/covid-19/your-contract/covid-19-yourterms-and-conditions/your-terms-and-conditions-all-doctors [Accessed 16 May 2020].

10 Department for Environment, Food and Rural Affairs, Department for Business, Energy and Industrial Strategy, Eustice G, Sharma A. Rules on carrying over annual leave to be relaxed to support 
key industries during COVID-19. Available from: www.gov.uk/ government/news/rules-on-carrying-over-annual-leave-tobe-relaxed-to-support-key-industries-during-covid-19 [Accessed 1 April 2020].

11 Academy of Medical Royal Colleges Trainee Doctors' Group. Plans regarding trainee redeployment during the COVID-19 pandemic. AoMRC 2020. Available from www.aomrc.org.uk/wp-content/ uploads/2020/03/200326_ATGD_COVID-19-redeployment_full. pdf [Accessed 1 April 2020].
12 British Medical Association. COVID-19: managing junior doctor rota changes in England. BMA, 2020. Available from: www.bma. org.uk/advice-and-support/covid-19 [Accessed 16 May 2020].

Address for correspondence: Dr Matthew Roycroft, Geriatric and Stroke Medicine Dept, Northern General Hospital, Herries Road, Sheffield S5 7AU, UK.

Email: matthew.roycroft@nhs.net 